\title{
Nietzsche leitor de Shakespeare
}

\author{
Pedro Süssekind*
}

\begin{abstract}
Resumo: O artigo analisa, a partir de referências feitas por Harold Bloom em seu estudo Shakespeare: a invenção do humano, passagens nas quais Nietzsche propõe interpretações de duas tragédias de Shakespeare. Uma dessas passagens, retirada de Aurora, defende uma compreensão de Macbeth que escape da avaliação moralista do protagonista. A outra passagem é do primeiro livro de Nietzsche, $O$ nascimento da tragédia, e diz respeito a uma das questões mais debatidas na recepção de Hamlet: o motivo da hesitação do príncipe, sua demora em agir diante das circunstâncias que lhe são apresentadas no primeiro ato da tragédia. Palavras-chave: Nietzsche - Shakespeare - Macbet - Hamlet
\end{abstract}

\section{Antigos e shakespearianos}

Duas referências fundamentais demarcaram a política cultural na Alemanha a partir de meados do século XVIII: os gregos antigos e o teatro shakespeariano. Por um lado, desde Winckelmann, o modelo da Grécia clássica foi considerado como ideal artístico e humanista a ser imitado. Por outro lado, a partir da proposta de um novo paradigma para o teatro nacional, feita por Lessing, a obra de Shakespeare se converteu no impulso para a revolução promovida pelo Sturm und Drang e pelo movimento romântico. ${ }^{1}$

A respeito do peso que teve o "helenismo" para o desenvolvimento cultural daquele período, considero bastante instrutivo o título de um importante estudo sobre o tema, publicado em 1958:

\footnotetext{
* Professor da Universidade Federal Fluminense (UFF), Rio de Janeiro, Brasil. E-mail: Pedro. sussekind@terra.com.br.

1 Cf. SÜSSEKIND, P. Shakespeare, o gênio original. Rio de Janeiro: Zahar, 2008.
} 
Süssekind, P.

A tirania da Grécia sobre a Alemanha, de Eliza Marion Butler. Com base em suas análises de Goethe, Schiller, Hölderlin e outros, a autora constata: "a Grécia de Winckelmann foi o fator essencial no desenvolvimento da poesia alemã ao longo da segunda metade do século XVIII e de todo o século XIX". ${ }^{2}$ Só que essa "tirania" é ainda mais ampla do que a frase indica, porque a obrigatoriedade do modelo grego não se restringiu à poesia; ela se desenvolveu também em outras áreas da cultura, repercutindo nos desdobramentos da Filosofia da História e da Filologia Clássica ao longo do século XIX.

Sob a ótica da tradição poética, filosófica e filológica constituída na Alemanha, Nietzsche certamente pode ser considerado como herdeiro daquele reinado tirânico da Grécia como modelo cultural. Isso fica evidente em seu primeiro livro - publicado, aliás, quando ele era professor de filologia -, no qual ele mencionava a "nobilíssima luta de Goethe, Schiller e Winckelmann pela cultura" como o tempo em que o espírito alemão se esforçou com mais vigor para aprender dos gregos (GT/NT 20, KSA 1.131). ${ }^{3}$ Se a aspiração de "chegar por uma mesma via à cultura e aos gregos" tinha se tornado cada vez mais fraca na Alemanha ao longo do século XIX, o autor concebia o projeto filosófico de $O$ nascimento da tragédia como um aprofundamento do esforço de seus precursores. Nesse caso, uma crítica do escopo do helenismo alemão sob a responsabilidade dos filólogos do século XIX está por trás das teses de Nietzsche, interessado em resgatar a luta pela cultura contida no projeto winckelmanniano de imitação dos antigos. ${ }^{4}$

Entretanto, em contraposição ao helenismo que marcou a hitoriografia, a filosofia e a poesia na Alemanha, o modelo shakespeariano foi proposto justamente como uma ruptura moderna em relação à necessidade de imitar os clássicos. Para usar a metáfora

2 Butler, E. M.. The tiranny of Greece over Germany. Cambridge: University Press, 1935, p. 6.

3 Tradução brasileira, p.121 (vide "referências bibliográficas").

4 Convém lembrar a polêmica despertada pelo livro entre os filólogos da época. Cf. Nietzsche e a polêmica sobre $O$ nascimento da tragédia, longo debate entre os filólogos da época.

174 | cadernos Nietzsche 31, 2012 
empregada por Butler, pode-se afirmar, então, que se trata de uma contestação da tirania do classicismo. Pioneiro nessa proposta, em suas Cartas sobre a nova literatura, de 1759, Lessing considerava que os autores de seu país se equivocavam ao seguir o ideal de teatro rigoroso importada da França e da Itália. Assim, Shakespeare constituía um antídoto contra a normatividade do teatro clássico, baseado nas regras poéticas provenientes da leitura de Aristóteles feita por Castelvetro, Boileau e Corneilles. A valorização do dramaturgo inglês como um poeta moderno que não segue as regras da arte - portanto de um gênio artístico definido pela originalidade - marcou época a partir da proposta de Lessing, como constatamos pelos desdobramentos da questão nas obras de Herder e Goethe relacionadas ao Sturm und Drang, nos textos de Friedrich Schlegel e de outros teóricos do Romantismo, ou mesmo nas filosofias do trágico desenvolvidas por Schelling, Hegel e Schopenhauer.

Embora essa referência não seja, em sua obra, um tema tão frequente nem tão importante quanto o helenismo, Nietzsche também pode ser considerado um herdeiro dessa tradição "shakespeariana" alemã que marcou profundamente o surgimento do Romantismo. Há comentários sobre Hamlet, Macbeth ou Rei Lear espalhadas pelas obras do filósofo, cada um deles subordinado a um contexto e a um objetivo específicos. Mas encontram-se também, igualmente dispersas, algumas breves e contundentes observações sobre o dramaturgo, expressas num tom que remete às analogias de Lessing, Herder e Goethe, em seus textos de defesa apaixonada do interesse por Shakespeare na Alemanha moderna, contra o privilégio exclusivo do teatro antigo ${ }^{6}$. A mais digna de nota entre essas observações gerais feitas por Nietzsche talvez

5 Apresentei a proposta de Lessing no livro Shakespeare, o gênio original, op.cit., p. 35-44.

6 Cf. LESSING, G. E.. De teatro e literatura. São Paulo, Editora Herder, 1964; HEDER. "Shakespeare". In: ROSENFELD, A. Autores pré-românticos alemães. Trad. João Hamann. São Paulo: EPU, 1992; GOETHE. "Para o dia de Shakespeare". In: Escritos sobre literatura. Trad. Pedro Süssekind. Rio de Janeiro: 7letras, 2000. 
seja a passagem de Além do bem e do mal em que Shakespeare é avaliado como "estupenda síntese hispano-moura-saxã do gosto, que faria um antigo ateniense das relações de Ésquilo morrer de riso e de raiva".7 Mas para "nós", diz o filósofo, para os alemães, para os "homens do sentido histórico", para os "homens modernos semi-bárbaros", cai bem a "selvagem policromia" do teatro shakespeariano, essa "miscelânea do que é mais delicado, mais selvagem e mais artificial" (JGB/BM 224, KSA 5.159).

Considero que as observações a respeito das peças de Shakespeare na obra de Nietzsche podem ser lidas segundo duas perspectivas distintas: é possível recorrer às questões extraídas do universo shakespeariano para delinear, com contornos precisos, as imagens de pensamento elaboradas pelo filósofo; ou é possível descobrir, naqueles comentários, indicações que permitem enxergar dimensões novas, perspectivas críticas de interpretação e de compreensão das questões apresentadas nos próprios dramas. Segundo a primeira perspectiva, de um leitor de Nietzsche, os trechos sobre Shakespeare não só ilustram, como também intensificam determinados temas, tomando emprestados o vigor e a complexidade dos personagens das peças. De acordo com a segunda perspectiva, de um leitor de Shakespeare, em que pese o estilo polêmico e incisivo de Nietzsche como intérprete, os seus comentários constituem vias de reflexão que põem em xeque toda uma tradição de leitura constituída sobre as bases das concepções morais que articularam e articularam os juízos estéticos.

A segunda perspectiva me interessa mais aqui, pois a proposta deste estudo é justamente pensar Nietzsche como leitor de Shakespeare. E um indício claro da importância de sua leitura é a presença das interpretações propostas pelo filósofo, ainda hoje, nos estudos shakespearianos. Para exemplificar essa presença, recorro a um dos mais conhecidos e divulgados desses estudos, Shakespeare:

7 Tradução brasileira, p.129-30 (vide "referências bibliográficas"). 
a invenção do humano, livro publicado em 1998, no qual Harold Bloom menciona diversas vezes observações de Nietzsche que são decisivas especialmente para entender a psicologia dos grandes protagonistas trágicos. Comentários sobre Hamlet e Macbeth extraídos de $O$ nascimento da tragédia e de Aurora são usados pelo autor para aprofundar as análises dessas tragédias, nos capítulos do estudo dedicados a elas. E esse uso, da maneira como é feito, me parece indicar não só a relevância e a atualidade, como também a profundidade da leitura elaborada nas passagens citadas.

De um modo geral, quando defende a hipótese de uma "invenção do humano" - ou seja, de que as criações poéticas shakespearianas podem ser lidas como uma espécie de nascimento da compreensão do ser humano tal como o entendemos na época moderna -, Bloom talvez demonstre afinidade com procedimentos genealógicos da filosofia nietzschiana. Mas essa afinidade permanece implícita, e o que chama a atenção nas referências diretas ao filósofo em Shakespeare: a invenção do humano é outro aspecto, que diz respeito à maneira de ler as tragédias. Evidentemente, o propósito original dos trechos citados pelo crítico não era o mesmo de um "shakespearianólogo", cujos comentários minuciosos de cada peça constituem um foco central e um ponto de partida para o desenvolvimento de uma reflexão abrangente sobre a obra do dramaturgo. Trata-se mais de um procedimento de apropriação, pois imagens e personagens shakespearianos são usadas pelo filósofo para caracterizar ou exemplificar determinadas ideias. Entretanto, os comentários em questão descortinam elementos das criações literárias de Shakespeare que permaneciam ocultos, seja por leituras superficiais, seja por uma tradição de avaliações anteriores à qual escapava, muitas vezes, o essencial.

Nietzsche desafia o leitor a entender as tragédias de Shakespeare para além de juízos de valor posteriores. Com ele se aprende que a moralidade e a sensibilidade de épocas refinadas podem impedir a interpretação da verdadeira natureza dos grandes protagonistas trágicos. Se, como leitor de Hamlet e Macbeth, ele 
Süssekind, P.

pode ser considerado um herdeiro do debate alemão em torno do dramaturgo, é porque leva às últimas consequências esse desafio crítico. Pois, na revisão pela qual a obra shakespeariana passou na Alemanha, a partir do final do século XVIII, justamente a noção de uma finalidade moral, ou efeito moral - ideia que pautava as poéticas classicistas no século XVII - tinha contribuído para as avaliações negativas do dramaturgo inglês que ainda dominavam a teoria do teatro quando Lessing passou a valorizá-lo e quando começou a despontar o movimento romântico.

\section{O demoníaco em Macbeth}

O momento em que o apreço de Harold Bloom pelas interpretações propostas por Nietzsche se torna mais evidente é, com certeza, a análise de Macbeth, na Parte VI ("As grandes tragédias") de Shakespeare: a invenção do humano. Nesse capítulo, ele cita todo o longo parágrafo da seção 240 de Aurora intitulado "Da moralidade da cena", no qual o filósofo alemão interpretava a questão da ambição do protagonista Macbeth, portanto o tema central da tragédia. Adotando, no parágrafo citado, a posição de um estudioso de Shakespeare, Nietzsche dialoga diretamente com toda uma tradição de leituras que consideravam o personagem segundo a ótica da moralidade: "Aquele que imagina que o teatro de Shakespeare produziu efeito moral e que a visão de Macbeth afasta irresistivelmente dos perigos da ambição engana-se" (Cf. M/A, KSA 3.201) $)^{8}$.

Nietzsche contesta a visão de que a peça tem um efeito moral, uma mensagem pedagógica, de acordo com a expectativa horaciana das poéticas classistas de que o bom teatro deve "unir o útil ao

8 Cf. BLOOM, H. A invenção do humano. Trad. José Roberto O' Shea. Rio de Janeiro: Objetiva, 2001, p. 651. O trecho citado na edição brasileira é da tradução portuguesa de Rui Magalhães (Nietzsche. Aurora. Porto: Rés, s.d., p. 155-6).

178 | cadernos Nietzsche 31, 2012 
agradável". ${ }^{9}$ A tendência tradicional seria a de ler a tragédia como se ela veiculasse o ensinamento de que é preciso afastar-se dos perigos da ambição desenfreada. Mas, segundo o filósofo, o sentido da força poética de Macbeth é justamente o inverso: quem possui uma ambição furiosa, ainda que velada, contempla no protagonista shakespeariano a sua própria imagem. O personagem exerceria, assim, uma "atração demoníaca" capaz de impelir naturezas semelhantes a imitá-lo, ou seja, a seguir sua obsessão, a tomar "o mais condimentado ingrediente na bebida ardente desta volúpia" que se desenvolve na cena.

Desse modo, segundo a avaliação de Nietzsche, um poeta trágico como Shakespeare não previne contra os riscos inerente à vida, mas considera como o encanto dos encantos essa existência apaixonada, mutável, perigosa, sombria, que a própria vida se mostra. "Demoníaco" significa, aqui, o modo de agir que despreza interesse e sobrevivência em benefício de uma ideia e de um instinto. Seria esse o cerne da ambição, como Nietzsche argumenta a partir de outro exemplo literário: "Pensais pois que Tristão e Isolda deram uma lição contra o adultério porque morreram os dois?", pois muito pelo contrário. Esse tipo de avaliação moral seria "virar os poetas de cabeça para baixo", e justamente os poetas, sobretudo grandes criadores como Shakespeare, "são apaixonados da paixão em si e de modo algum das disposições mórbidas que acompanham quando o coração não tem na vida mais do que uma gota no fundo do corpo"10.

Do ponto de vista de seu propósito no contexto da filosofia de Nietzsche, esse comentário tem o sentido de criticar não só a moralidade da nossa tradição, na qual se baseia uma avaliação falsa das situações humanas, como também o tempo presente, no qual essa perspectiva moralista impede a compreensão da força poética

9 Segundo a fórmula de Horácio: "Arrebata todos os sufrágios quem mistura o útil e o agradável, deleitando e ao mesmo tempo instruindo o leitor”. Cf. Horácio. Arte poética. In: A poética clássica, p. 65.

10 BLOOM, H. A invenção do humano, op. cit., p. 651. 
de Shakespeare. O final da seção menciona a dimensão temporal, contrapondo à visão debilitada do presente (no caso, o final do século XIX) o vigor da época em que a peça foi escrita. Shakespeare nos falaria desde o "interior de uma época agitada e forte que semiembriaga e atordoa com a sua abundância de sangue e de energia,de uma época pior do que a nossa". Por isso, como explica filósofos, "nós", os homens modernos civilizados com escrúpulos morais da época de Nietzsche, seríamos "obrigados a modificar e a adaptar a nós o objetivo de um drama shakespeariano". E isso significa simplesmente "não o compreender"

Quando Harold Bloom cita essa passagem, ele pretende exatamente explicar uma espécie de simpatia irracional que o leitor sente por Macbeth, embora o personagem seja talvez o mais sanguinário dos tiranos-vilões shakespearianos. $\mathrm{O}$ mistério desse protagonista, um herói épico que se torno vilão, estaria ligado ao efeito extraordinário de identificação com aquilo mesmo que, do ponto de vista moral, aparece como terrível e condenável. ${ }^{12}$ Nessa interpretação da dignidade trágica de Macbeth, Bloom demonstra que nossa capacidade de percebê-la depende da capacidade que "o personagem tem de fazer valer a sua percepção de formas de vida desconhecidas, de forças que estão além de Hécate e das bruxas". Tais forças diriam respeito à tragicidade em sua forma mais pura e assustadora, ligada ao destino. Assim, segundo o crítico, Shakespeare investiga em Macbeth a presença demoníaco no próprio homem. À maneira de um espelho, como indicava Nietzsche, o absurdo e a falta de sentido da ambição de Macbeth mostram-se demasiadamente humanos, não como traços condenáveis de um vilão que o leitor julga à distância, mas como o resultado de forças que assumem o comando da peça e diante das quais os preconceitos da moralidade são irrelevantes. Essas forças

11 Ibid.

12 Ibid., p. 652.

180 | cadernos Nietzsche 31, 2012 
nos aterrorizam, mas ao mesmo tempo trazem alegria, "um imenso prazer que se deixa contaminar pelo demoníaco", como diz Bloom, porque elas se revelam no coração do homem e não em qualquer instância externa ou transcendente.

Macbeth deseja demais, e por isso mesmo não deseja nada. É a interpretação de Nietzsche que permite ao crítico compreender o personagem para além de uma leitura moralizante, como essa figuração do homem que exprime uma negatividade radical. Desse modo, é a concepção do demoníaco indicada por Nietzsche que funciona como uma chave para a compreensão daquela "marcha fúnebre niilista", como a caracteriza Harold Bloom, ${ }^{13}$ que se expressa na famosa fala do protagonista após a morte de Lady Macbeth:

Amanhã, e amanhã, e ainda outro amanhã arrastam-se nesta passada trivial do dia para a noite, da noite para o dia, até a última sílaba do registro dos tempos. E todos os nossos ontens não fizeram mais que iluminar para os tolos o caminho que leva ao pó da morte. Apaga-te, apaga-te, chama breve! A vida não passa de uma sombra que caminha, um pobre ator que se pavoneia e se aflige sobre o palco - faz isso por uma hora e, depois, não se escuta mais sua voz. É uma história contada por um idiota, cheia de som e fúria e vazia de significado $^{14}$.

\section{Hamlet e o homem dionisíaco}

Em Shakespeare: a invenção do humano, Harold Bloom elogia a "memorável interpretação de Hamlet" feita por Nietzsche, ${ }^{15}$ referindo-se ao trecho de $O$ nascimento da tragédia em que o filósofo adota a postura do protagonista da peça de Shakespeare como um símbolo de um dos principais elementos da sua concepção do

13 Ibid., p

14 Shakespeare. Macbeth, Ato V, Cena 5.

15 BLOOM, H. op. cit., p. 490. 
Süssekind, P.

trágico. Nietzsche se interessa especialmente pela situação descrita no início de Hamlet, porque se trata de circunstâncias nas quais repousa, sob uma aparente felicidade, uma verdade profunda e terrível. Por trás das condições exteriores do reino da Dinamarca, por trás da ilusão, por trás da beleza e da ordem disfarçadas pela festividade das bodas dos soberanos, esconde-se "algo podre": o assassinato do rei legítimo por seu próprio irmão usurpador, um regicídio e um fratricídio ao mesmo tempo, o pior crime que se poderia imaginar.

Segundo a perspectiva de Nietzsche, o lado terrível da existência, com suas motivações violentas, avassaladoras e inconfessáveis, sustentaria o mundo das aparências em que os homens desempenham seus papéis. Hamlet, como um personagem altamente filosófico, é quem conhece essa verdade mais profunda e, por isso mesmo, encara com enfado ou horror a situação à sua volta. Esse caráter filosófico se evidencia, em Hamlet, já na primeira cena em que o protagonista se manifesta, de olhos baixos e com nuvens sombrias em seu semblante, de luto em meio à celebração geral, antes mesmo de ouvir o fantasma de seu pai lhe revelar o que há por trás da situação. "Não conheço o parece", afirma Hamlet, quando responde à rainha, que fizera uma pergunta sobre o fato de a morte, algo natural, parecer-lhe tão singular ${ }^{16}$. Nessa perspectiva melancólica do príncipe, a essência - o lado sombrio e aterrador da existência, o horror e o absurdo, a atração do suicídio - se opõe às ilusões da bela aparência, à ordem, aos limites frágeis em que se apóiam as convenções humanas.

$\mathrm{Na}$ conhecida caracterização de Nietzsche em $O$ nascimento da tragédia, o impulso artístico dionisíaco, descrito por analogia com a embriaguez, consiste inicialmente num estado de êxtase, na harmonia de todos os seres, no esquecimento e na fusão com a natureza, portanto na perda da individualidade que se revela tão

16 Hamlet, Ato I, Cena 2.

182 | cadernos Nietzsche 31, 2012 
importante para os valores heróicos da arte grega. Esse impulso se opõe àquele do sonho, que caracteriza por analogia o apolíneo como um impulso artístico de formação de imagens, de beleza, de ordenamento. As manifestações do dionisíaco teriam vindo de fora da Grécia, pois estavam presentes nas celebrações asiáticas caracterizadas por uma desenfreada licença sexual, pela perda de todo ordenamento social e dos laços familiares, por "uma horrível mistura de volúpia e crueldade" (GT/NT 2, KSA 1.33) ${ }^{17}$. Trata-se, assim, de um impulso que tende a ser aniquilador e que, depois de ter levado à desagregação determinados povos do oriente, ameaçava a cultura apolínea da Grécia Antiga. Em "A visão dionisíaca do mundo", um texto preparatório para seu livro sobre o nascimento da tragédia, Nietzsche associava o dionisíaco ao mundo titânico das Górgonas e Eríneas, que na mitologia grega se encontram em conflito com os deuses olímpicos. As divindades dionisíacas, titânicas, são pensadas como essencialmente impiedosas, sem traço de compaixão ou reparação, "parentes da verdade", da noite, do sofrimento e da morte. Numa primeira imagem do efeito que tais divindades produzem, o filósofo afirma que todas elas são como a Medusa, pois contemplar seu aspecto terrível transforma em pedra (DW/VD 2, KSA 1.560). Com essa metáfora, ele procura expressar como a invasão da torrente dionisíaca seria algo de insuportável e aniquilador, algo que paralisa, porque quando alguém enxerga o cerne da terrível ação destrutiva da história universal e da crueldade insaciável da natureza, toda e qualquer ação se mostra vã.

É justamente no trecho de $O$ nascimento da tragédia sobre esse tema que Nietzsche recorre a Hamlet. O príncipe dinamarquês é comparado ao "homem dionisíaco", porque "ambos lançaram alguma vez um olhar verdadeiro à essência das coisas, ambos passaram a conhecer e a ambos enoja atuar". E o filósofo complementa sua comparação: "pois sua atuação não pode modificar em nada a eterna

17 Tradução brasileira, p.33 (vide "referências bibliográficas"). 
Süssekind, P.

essência das coisas", e tanto Hamlet quanto o homem dionisíaco, citando a célebre frase acerca do tempo fora dos eixos, "sentem como algo ridículo e humilhante que se lhes exija endireitar de novo o mundo que está desconjuntado" (GT/NT 7, KSA 1.57) ${ }^{18}$.

Segundo esse argumento, quem olhou na essência das coisas tem nojo de agir e permanece imobilizado: "O conhecimento mata a atuação, para atuar é preciso estar velado pela ilusão", confirma Nietzsche, expressando a lição hamletiana que está por trás da constatação de que a verdade dionisíaca, como a Medusa, ameaça petrificar quem a contempla. Hamlet configuraria assim, como uma espécie de personagem conceitual, a ideia do "homem dionisíaco" que Nietzsche desenvolve em seu primeiro livro. A hesitação do protagonista mais famoso de Shakespeare exemplifica o estado de paralisia associado ao conhecimento de uma verdade por trás do mundo das aparências.

Por outro lado, como dá a entender Harold Bloom ao recorrer a Nietzsche em sua análise de Hamlet, na parte VI de Shakespeare: $a$ invenção do humano, o filósofo faz um exercício de crítica literária ao se posicionar, em seu primeiro livro, em relação a uma das mais polêmicas questões discutidas no contexto da recepção da tragédia: o verdadeiro motivo da hesitação do príncipe dinamarquês. Para Nietzsche, em sua "memorável interpretação", é preciso descartar a visão do personagem como um sonhador que pensa demais e que, devido ao excesso de opções, não consegue agir. Não se trata de pensar demais, como explica Bloom com base em Nietzsche, e sim de pensar com extrema clareza: é o próprio conhecimento que mata a ação, pois ela precisa dos véus da ilusão para ser realizada, "esta é a doutrina" (GT/NT 7, KSA 1.57) ${ }^{19}$.

18 Tradução brasileira, p.56 (vide "referências bibliográficas").

19 Ibid., p. 56. Cf. BLOOM, H. op. cit. p. 490

184 | cadernos Nietzsche 31,2012 


\section{A filosofia de Hamlet}

Caracterizado como um homem que contempla a verdade, o personagem de Shakespeare pode ser considerado um autêntico filósofo, não como símbolo da abstração que se afasta da realidade, mas como expressão de um conteúdo mais profundo do saber. Essa interpretação de Hamlet como filósofo não é explicitada diretamente no Nascimento da tragédia, mas sim quando Nietzsche volta a avaliar a peça em Ecce Homo, um dos seus últimos livros, no qual ele faz um balanço de sua vida e de sua obra. No capítulo "Por que sou tão esperto", o autor pergunta: "Compreende-se Hamlet?". $\mathrm{E}$ a resposta para essa pergunta que anuncia uma interpretação a contrapelo vem em seguida, numa única frase: "Não a dúvida, a certeza é que enlouquece" (EH/EH, "Por que sou tão esperto, 4, KSA 6.287$)^{20}$. É assim que Nietzsche compreende Hamlet, conforme já indicava a leitura feita em $O$ nascimento da tragédia.

$\mathrm{O}$ grande personagem de Shakespeare, apesar de todas as suas hesitações, reflexões e dúvidas sobre o curso das ações, é atormentado não pela falta, não pela indecisão, mas justamente pela certeza, ou seja, pela confirmação da verdade. É por saber que ele parece insensato, é seu conhecimento que o atormenta. "Mas é preciso ser fundo, ser abismo, filósofo, para assim sentir", Nietzsche diz, pois "todos nós tememos a verdade". É preciso ser filósofo para assim sentir o Hamlet e, portanto, para compreender a verdade da peça, pois trata-se aqui, em Ecce Homo, do peso e do risco inerentes à filosofia. Por outro lado, para quem pretende interpretar a peça de Shakespeare, a passagem indica que o próprio Hamlet precisa ser um filósofo para sentir a verdade desta inversão: não a dúvida, a certeza é que enlouquece. Afinal, é com base nessa convicção que o príncipe adotará como lema a ideia de que "a prontidão é tudo"

20 Tradução brasileira, p.143 (vide "referências bibliográficas"). 
$\mathrm{e},{ }^{21}$ no último ato, será capaz de expressar em ação, no desfecho trágico da peça, aquela verdade terrível que só ele conhecia.

Como todo protagonista trágico de Shakespeare, Hamlet não é um personagem estanque, ele passa por uma mudança ao longo da tragédia. Com isso, depois de confirmar por meio de um artifício teatral a culpa do rei usurpador, de confrontar sua mãe e de, sem intenção, sujar suas mãos com o sangue de Polônio, o príncipe do último ato já deixou de lado as hesitações suicidas de seus solilóquios anteriores. O Hamlet que retorna de uma aventura com piratas e que contempla o exército de Fortimbrás assume, afinal, a realização da tarefa que lhe fora imposta. De acordo com uma ótica nietzschiana, a transformação do personagem no decorrer da peça pode ser interpretada como a aceitação de uma visão dionisíaca do mundo, como um gesto afirmativo diante do terror, uma ação capaz de fazer o veneno que corrompia o reino da Dinamarca destronar o próprio agente desse veneno, que usurpava o trono, para dar lugar a um sucessor com a tarefa de restabelecer a ordem. O resto é silêncio, mas cabe a Horácio transmitir para a posteridade o que nós como espectadores já sabemos: a verdade aterrorizante e imobilizadora que se esconde por trás da cena trágica.

\begin{abstract}
This paper analyzes, based on references made by Harold Bloom in his study Shakespeare: the invention of the human, passages in which Nietzsche proposes ways to read and understand two Shakespearean tragedies. One of these passages, taken from Aurora, justifies an understanding of Macbeth that escapes from the moral evaluation of the protagonist. The other passage is from Nietzsche's first book, The Birth of Tragedy, and concerns the interpretation of one of the most debated issues in the reception of Hamlet: the reason for the hesitation of the prince, under the circumstances presented in the first act of the tragedy.
\end{abstract}

Keywords: Nietzsche - Shakespeare - Macbeth - Hamlet

21 Hamet. Ato V, Cena 2.

186 | cadernos Nietzsche 31, 2012 


\section{referências bibliográficas:}

1. HORÁCIO. Arte poética, in: ARISTÓTELES, HORÁCIO, LONGINO. A poética clássica. Trad. Jaime Bruna. São Paulo: Cultrix, 1981.

2. BLOOM, Harold. Shakespeare: a invenção do humano. Trad. José Roberto O'Shea. Rio de Janeiro: Objetiva, 2001.

3. BUTLER, E. M.. The tiranny of Greece over Germany. Cambridge: University Press, 1935.

4. GOETHE. "Para o dia de Shakespeare". In: Escritos sobre literatura. Trad. Pedro Süssekind. Rio de Janeiro: 7letras, 2000.

5. HERDER. "Shakespeare". In: ROSENFELD, A. Autores pré-românticos alemães. Trad. João Hamann. São Paulo: EPU, 1992.

6. LESSING, G. E. De teatro e literatura. São Paulo: Editora Herder, 1964.

8. MACHADO, R. (org). Nietzsche e a polêmica sobre O nascimento da tragédia. Rio de Janeiro: Zahar, 2005.

5. NIETZSCHE. Sämtliche Werke. Kritische Studienausgabe. München: DTV, 1980.

. O nascimento da tragédia. Trad. J. Guinsburg. São Paulo: Companhia das letras, 1993.

. Além do bem e do mal. Trad. Paulo César de Souza. São Paulo: Companhia das letras, 1992.

. Ecce Homo. Trad. Paulo César de Souza. São Paulo: Companhia das letras, 2007. . Aurora. Trad. Paulo César de Souza. São Paulo: Companhia das letras, 2008.

6. SHAKESPEARE, William. Four great tragedies. Nova York: Signet Classics, 1998. . Teatro completo. Tragédias. Trad. Carlos Alberto Nunes. São Paulo: Ediouro, s/d.

. Hamlet. Trad. Millor Fernandes. Porto Alegre: LPM, 2005.

. Macbeth. Trad. Beatriz Viegas-Faria. Porto Alegre: LPM, 2000.

7. SÜSSEKIND, P. Shakespeare, o gênio original. Rio de Janeiro: Zahar, 2008.

Artigo recebido em 08/06/2011.

Artigo aceito para publicação em 10/08/2011. 